\title{
Developmental g: Lost in the Construct Jungle
}

\author{
Commentary on Demetriou
}

Ulrich Müller Mauricio Garcia-Barrera

University of Victoria, Victoria, BC, Canada

\begin{abstract}
Keywords
Developmental $g$. Structure of intelligence $\cdot$ Cognitive development $\cdot$ Executive function
\end{abstract}

Demetriou, Makris, Spanoudis, Kazi, Shayer, and Kazali [2018, this issue] present an ambitious theory that integrates two lines of inquiry: research on the structure of intelligence and research on cognitive development. The key claims of their theory are that (a) general intelligence $(g)$ is constituted by attention control, flexibility, working memory, cognizance, and inference; (b) the relations between the processes constituting $g$ change with development, and (c) the interactions between the five processes are coordinated by a mechanism that includes abstraction, representational alignment, and cognizance. Demetriou et al. summarize a remarkable set of theoretical and empirical research in support of their theory. It has become rare to see a theory with such a broad scope. At the same time, any ambitious theory requires clarification and generates a lot of questions to be addressed by future research. In our commentary, we raise questions with respect to the relations between executive control (or executive function $[\mathrm{EF}]$ as it is usually called) and $g$, the developmental cycles, and the implications of the theory of Demetriou et al. for real-time dynamic cognitive functioning.

As Demetriou et al. point out, there are numerous studies that show strong relations between $\mathrm{EF}$ and $g$. Several interpretations of this relation have been provided, and consensus has not been reached [Blair, 2006]. Both constructs have been consistently defined in terms of sets of interactive cognitive abilities that facilitate our understanding of complex ideas and situations, allowing us to sort out environmental contingencies and guide the production of behaviors needed for effective problem solving and adaptation to the environment [for a discussion, see Duggan \& Garcia-Barrera, 2015].

Given the strong relations between EF and $g$, it is very important to situate clearly the commonalities and differences between these two constructs. However, Demetriou and colleagues' treatment of this issue is not entirely satisfactory. To start, they do not

\section{KARGER}

E-Mail karger@karger.com www.karger.com/hde (c) 2018 S. Karger AG, Basel 
provide a consistent approach to the construct of EF. For instance, Demetriou et al. include in their definition of general information processing attention control, shifting, and working memory, which have traditionally been classified as components of EF [e.g., Miyake et al., 2000]. Later, they seem to separate executive control from flexibility and working memory, defining them as "autonomous and distinct contributors of $g$." Further, in their formula $g=f$ (attention control + flexibility + working memory + cognizance + inference), they seem to equate attention control with executive control but are inconsistent with the way in which they treat these terms in other places of their paper (e.g., "aspects of executive control, such as attention control and working memory;" increases in intelligence "may transfer top-down to executive control and working memory").

The problems arising from the inconsistent treatment of EF are further exacerbated by the way in which Demetriou et al. conceptualize cognizance. Cognizance is defined as "a unifying force," a monitoring system of sorts that engages as a side effect of the failure of the other systems "needing to choose between stimuli or possible actions turns the 'mind's eye' to them, thereby bringing them into the focus of awareness." In many respects, cognizance seems to be similar to the supervisory attentional system, an executive control system introduced by Norman and Shallice [1986]. Thus, it appears that cognizance and attention/executive control are indistinguishable, yet forced to be independent in the formula for $g$. Because Demetriou et al. further state that executive control is "shared by all inferential processes," the formula $g=f$ (attention control + flexibility + working memory + cognizance + inference) essentially boils down to $g=f($ executive control).

The identification of $g$ and EF, however, runs counter to the intention of Demetriou et al. and is contradicted by empirical evidence. In his comprehensive review, Blair [2006] presents compelling evidence in support of the differentiation between fluid cognition (i.e., EF) and intelligence. Similarly, using a latent variable approach to define executive function, Friedman et al. [2006] demonstrated that among inhibiting, shifting, and updating working memory representations, only updating was significantly associated with both crystallized (vocabulary and WAIS information) and fluid intelligence (WAIS blocks design and Raven test). Some of the conceptual issues emerge from construct conflation without specifying how the two are distinguishable. In this regard, Duggan and Garcia-Barrera [2015] suggest that both higher-order aspects of cognition (i.e., $\mathrm{EF}$ and $g$ ) can be defined as outcomes of mental operations drawing from a common pool of cognitive resources, facilitated by processing speed (mental efficiency), working memory (mental capacity) and attention (mental engagement), in which intelligence (as in $g$ ) fully emerges in situations in which the complexity of the demands to the system is high, whereas EF emerges in situations which present the person with novel problems. Several situations share both types of demands and thus engage EF as well as $g$.

The implication for the integrated development approach by Demetriou et al. is that the constructs of EF and $g$ need to be clearly defined when studying their developmental trajectories, as these would be expected to be similar in some respects, or at least to influence each other. One framework that is helpful in this context is the differentiation hypothesis of the functional organization of cognitive abilities [Garrett, 1946]. Demetriou et al. discuss the differentiation hypothesis, but their theory fails to address two important empirical findings. First, it is unclear how the integration/differentiation process of their model integrates the developmental trajectory of EF [e.g., Lee, Bull, \& Ho, 2013; Müller \& Kerns, 2015]. The second issue regards how level of ability interacts with age during the process of differentiation. A recent meta-analysis examining the 
Spearman law of diminishing returns [Blum \& Holling, 2017] supported the differentiation hypothesis but also demonstrated an interaction between age and ability level and the strength of the correlations and $g$ loadings of cognitive ability tests in which they decreased with increasing ability, while they increased with age of the participant. If level of ability indeed plays a role, the claim of Demetriou et al. that "[d]ifferentiation from and intertwining of specific processes with $g$ is a developmental rather than an individual differences phenomenon" may have to be better supported by empirical evidence, and it must be contrasted with the extant literature in genetic predisposition and intergenerational transmission of intelligence and their impact on levels of ability.

Finally, the theory of Demetriou et al. faces another problem by virtue of the fact that $\mathrm{EF}$ and cognizance appear as processes at two different levels. On the one hand, they are part of the processes that constitute $g$. On the other hand, they are also involved in the mechanism that orchestrates the interactions between the different processes that constitute $g$. According to Demetriou et al., this mechanism includes three interdependent processes: (a) abstraction, (b) representational alignment, which is an executive control process, and (c) cognizance (AACog mechanism). Thus, the same processes (EF and cognizance) appear to be both regulators and being regulated. It is not clear whether this leads to an infinite regress. For example, does the relative importance of the different processes involved in AACog vary with developmental level? Which mechanism orchestrates the processes of the AACog mechanism? Clearly, the role of AACog in developmental $g$ needs to be elaborated, and Demetriou et al. should explain why the notion of AACog does not introduce a vicious cycle.

Let us move to the four developmental cycles outlined by Demetriou et al. Overall, the key features of these cycles are largely consistent with Piagetian or neo-Piagetian theories. However, Demetriou et al. appear to be not quite consistent in the description of the first developmental cycle ("episodic thought"). On the one hand, they characterize infants as mentalistic creatures who "represent themselves and others as representational beings," clearly following the rich interpretation of infants by neonativist researchers such as Baillargeon and colleagues [e.g., Baillargeon, Scott, \& Bian, 2016]. On the other hand, they provide a more lenient interpretation and describe awareness of action and action-object relations as explicit but awareness of intervening representations as implicit. The inconsistency remains to be resolved. The way this issue is addressed would have major implications for the whole theory. If Demetriou et al. subscribed to the rich, mentalistic interpretation, they would build their theory on shaky ground because the empirical findings that gave rise to the mentalistic interpretation of infants' behavior have come under attack [e.g., Kulke, Reiß, Krist, \& Rakoczy, in press], and the mentalistic interpretation has also been criticized for theoretical reasons [Carpendale \& Lewis, 2015]. In particular, by subscribing to the mentalistic interpretation, Demetriou et al. would inherit the problems of an empiricist representational theory of mind [Müller \& Giesbrecht, 2008; Müller \& Overton, 1998; Müller, Sokol, \& Overton, 1998] and forgo the solid grounding of representation in action [Allen \& Bickhard, 2013]. Furthermore, understanding oneself as representational being would imply some ability to objectify one's own mental life, and it is unclear where this ability would come from. One possibility is that it originates in social interaction and the taking of the attitude of another person toward oneself [Mead, 1934; see Müller \& Runions, 2003; Müller \& Carpendale, 2004], but the developmental processes and conditions that make mentalizing, representation, and reflection possible would need to be clarified by Demetriou et al. 
Let us discuss the last set of issues. The theory of Demetriou et al. is mainly a theory of the architecture of intelligence. As a consequence, the dynamic processes that are used by the person in real time are not elaborated. This omission has several repercussions. To begin with, the functional or dynamic relation between processes remains unclear. Demetriou et al. derive the processes using statistical procedures from a selected set of tasks. Because the processes were derived from different tasks, the relations between these processes are strictly statistical relations, and statements about their relations must be interpreted in this manner (e.g., "mental efficiency ... sending influences to working memory;" "the effect of perceptual awareness relations on the generative executive control factor." Moreover, it is likely that different processes might emerge if different tasks are provided. Consequently, the "developmental priorities in the construction of the general ability in each phase" themselves are constructed by the researchers who selected a particular set of performance measures. In order to examine their functional relations at different ages, the same task (e.g., tower of Hanoi) would have to be used, and thorough task analysis and experimental manipulation (e.g., increasing cognitive load to examine effects of increasing demands on working memory capacity; articulatory suppression to examine the effects of language as scaffold for task performance) would need to be conducted. For such an enterprise, the research by Demetriou et al. provides useful pointers for task selection and experimental manipulation. Another approach to demonstrating functional relations between different processes consists in the use of training studies. This approach was adopted by Demetriou et al., but, in our view, the training studies need to be more specific to test predictions about age- and phase-related changes in the processes, and it needs to be clarified what actually is being trained (e.g., in the research manipulating cognizance, were students made aware of their own mental processes or did they learn to understand the structure of the problem at a deeper level?).

In general, the theory by Demetriou et al. needs to be supplemented by a functional framework [e.g., for a functional framework for EF, see Zelazo, Carter, Reznick, \& Frye, 1997]. Within a functional framework, language may turn out to play a crucial role in cognizance and higher-order cognitive control processes, and its role may change with development [Müller \& Kerns, 2015]. Within a functional framework, relational complexity would be tied to the structuring activity of cognitive processes and not to complexity of concepts because the latter are constituted by the structuring activity of the mind [Müller et al., 1998]. Within a relational framework, cognizance would not be a factor derived from task performance, but a (more or less successful) step in attempting to overcome obstacles [Piaget, 1974/1976]. Finally, within a functional framework, the person would reemerge, not as placeholder for a conglomerate of interaction processes, but as an embodied, goal-oriented person who uses their cognitive skills to solve everyday problems.

In conclusion, we applaud the ambitious attempt by Demetriou et al. to reconcile different research traditions and integrate developmental research and individualdifference research on intelligence. However, we think that their theory needs to be further elaborated in terms of clarifying the relations between $g$, EF, and cognizance, and the developmental foundation and prerequisites of processes. Furthermore, ultimately, the structural theory needs to be incorporated into a functional framework. To paraphrase an expression by Kant, structures without functions are blind, and functions without structures are empty. 


\section{References}

Allen, J.W.P., \& Bickhard, M.H. (2013). Stepping off the pendulum: Why only an action-based approach can transcend the nativist-empiricist debate. Cognitive Development, 28, 96-133. doi:10.1016/j.cogdev.2013.01.002

Baillargeon, R., Scott, R.M., \& Bian, L. (2016). Psychological reasoning in infancy. Annual Review of Psychology, 67, 159-186. doi:10.1146/annurev-psych-010213-115033

Blair, C. (2006). How similar are fluid cognition and general intelligence? A developmental neuroscience perspective on fluid cognition as an aspect of human cognitive ability. Behavioral and Brain Sciences, 29, 109-125. doi:10.1017/S0140525X06009034

Blum, D., \& Holling, H. (2017). Spearman's law of diminishing returns. A meta-analysis. Intelligence, 65, 60-66. doi:10.1016/j.intell.2017.07.004

Carpendale, J.I.M, \& Lewis, C. (2015). The development of social understanding. In L. Liben \& U. Müller (Vol. Eds), R.M. Lerner (Ed.-in-Chief), Handbook of child psychology and developmental science. Vol. 2: Cognitive processes (7th ed., pp. 381-424). New York, NY: Wiley. doi:10.1002/9781118963418. childpsy 210

Duggan, E.C., \& Garcia-Barrera, M.A. (2015). Executive functioning and intelligence. In S. Goldstein, D. Princiotta, \& J.A. Naglieri (Eds.), Handbook of intelligence (pp. 435-458). New York, NY: Springer. doi:10.1007/978-1-4939-1562-0_27

Friedman, N.P., Miyake, A., Corley, R.P., Young, S.E., DeFries, J.C., \& Hewitt, J.K. (2006). Not all executive functions are related to intelligence. Psychological Science, 17, 172-179. doi:10.1111/j.14679280.2006.01681.x

Garrett, H.E. (1946). A developmental theory of intelligence. American Psychologist, 1, 372-378. doi: $10.1037 / \mathrm{h} 0056380$

Kulke, L, Reiß, M., Krist H., \& Rakoczy, H. (in press). How robust are anticipatory looking measures of Theory of Mind? Replication attempts across the life span. Cognitive Development. doi:10.1016/j. cogdev.2017.09.001

Lee, K., Bull, R., \& Ho, R.M. (2013). Developmental changes in executive functioning. Child Development, 84, 1933-1953. doi:10.1111/cdev.12096

Mead, G.H. (1934). Mind, self, and society from the standpoint of a social behaviorist. Chicago, IL: University of Chicago Press.

Miyake, A., Friedman, N.P., Emerson, M.J., Witzki, A.H., Howerter, A., \& Wager, T.D. (2000). The unity and diversity of executive functions and their contributions to complex "frontal lobe" tasks: A latent variable analysis. Cognitive Psychology, 41, 49-100. doi:10.1006/cogp.1999.0734

Müller, U., \& Carpendale, J.I.M. (2004). The development of social understanding in infancy. In J.I.M. Carpendale \& U. Müller (Eds.), Social interaction and the development of knowledge (pp. 215-238). Mahwah, NJ: Erlbaum.

Müller, U., \& Giesbrecht, G. (2008). Methodological and epistemological issues in the interpretation of infant cognitive development. Child Development, 79, 1654-1658. doi:10.1111/j.1467-8624.2008. 01216.x

Müller, U. \& Kerns, K. (2015). The development of executive function. In L. Liben. \& U. Müller (Vol. Eds.), \& R.M. Lerner (Series Ed.), Handbook of child psychology and developmental science. Vol. 2: Cognitive processes (7th ed., pp. 571-623). New York, NY: Wiley. doi:10.1002/9781118963418.childpsy214

Müller, U., \& Overton, W.F. (1998). How to grow a baby: A re-evaluation of image schema and Piagetian action approaches to representation. Human Development, 41, 71-111. doi:10.1159/000022570

Müller, U., \& Runions, K. (2003). The origins of understanding self and other: James Mark Baldwin's theory. Developmental Review, 23, 29-54. doi:10.1016/S0273-2297(03)00004-2

Müller, U., Sokol, B., \& Overton, W.F. (1998). Reframing a constructivist model of the development of mental representation: The role of higher-order operations. Developmental Review, 18, 155-201. doi:10.1006/drev.1997.0451

Norman, D.A., \& Shallice, T. (1986). Attention to action. In R. Davidson, R. Schwartz, \& D. Shapiro (Eds.), Consciousness and self-regulation: Advances in research and theory (pp. 1-18). New York, NY: Plenum Press. doi:10.1007/978-1-4757-0629-1_1

Piaget, J. (1976). The grasp of consciousness. Cambridge, MA: Harvard University Press (original work published 1974).

Zelazo, P.D., Carter, A., Reznick, J.S., \& Frye, D. (1997). Early development of executive function: A problem solving framework. Review of General Psychology, 1, 198-226. doi:10.1037/1089-2680.1.2.198 